\title{
Managing Masquerade Festivals for Tourism and Economic Gains: A Study of Mmanwu Festival in Anambra State
}

\author{
Clifford Nwanna \\ Department of Fine and Applied Arts, Faculty of Environmental Sciences, Nnamdi Azikiwe University, Nigeria
}

Copyright $\bigcirc 2017$ by authors, all rights reserved. Authors agree that this article remains permanently open access under the terms of the Creative Commons Attribution License 4.0 International License

\begin{abstract}
Nigeria has a lot of natural and man-made tourism potentials, which include: architectural edifices, Traditional/Contemporary drama, water falls, masquerade festivals among many others. These tourism potentials, if properly harnessed and sustained could be marketed for tourism and huge economic gains. Masquerade festivals in particular, appear to be one of the most neglected tourism events in Nigeria. The emergence and fast growing pace of the home movie industry in Nigeria, popularly known as Nollywood and the lackluster attitude of government, researchers and students toward traditional theatre are gradually forcing masquerade and the entire traditional theatre into extinction. This study is thus a conscious effort aimed at digging up the hidden treasures of traditional theatre in Nigeria and presenting its aesthetic and economic potentials to the global theatre landscape. A descriptive and qualitative research approach was employed in the study. It is hoped that this study will lead to a revival of interest in traditional masquerade festivals in Nigeria and reawaken a consciousness toward this direction.
\end{abstract}

Keywords Nollywood, Tourism, Traditional, Contemporary, Drama, Masquerade

\section{Introduction}

Tourism is one of the fastest growing industries in world. In fact, Tourism and hospitality industries have become the most important economic activities globally in the spirit of post- modernism and the increasing transformation they offer.

Although the exact origin of Tourism is still shrouded in obscurity, the existence of tourism could be traced back to the ancient times, since tourism could be viewed as a travel for recreational, leisure, business or health purposes. World Tourism Organization (WTO) defines tourism as
Activity or set of activities embarked upon by people who travel to, and stay in places outside usual environment for more than twenty-four hours and not more than one consecutive year for leisure, business and other purposes not related to exercise of any activity remunerated from within the place visited.[1]

Nigeria has plenty of natural and man-made tourism sites. These include, architectural edifices, water falls, masquerade festivals among many others. These tourism events, if properly harnessed and sustained could be marketed for huge economic gains. Masquerade festivals, in particular, appear to be one of the most neglected tourism potentials in Nigeria [2]. The variety, depth and vibrancy of Nigeria's traditional theatre cannot be questioned. Each region possesses a wealth of material that is clearly evident. In spite of the multiplicity of rich cultural festivals existing among the over 200 cultures, there is still insufficient effort at harnessing them for tourism [3]. In view of these, this study investigates Igbo mmanwu(masquerade) festival as a tourism potential. Masquerade Theater, among the Igbo of Nigeria is an evidence of their culture and the sum total or their ways of life from the ancient to the present time. Mmanwu (masquerades) have continued to be a dominant feature in African contemporary theater. In Africa, Masquerades played very crucial socio-political roles in addition to entertainment. Some early colonial ethnographers and anthropologists also showed a lot of interest in African masquerade theatre and prized the genre highly above others artistic genres in Africa [4]. This notwithstanding, there has not been sufficient conscious efforts to encourage the Mmanwu theater, in order to ensure its continuity. This situation is worrisome because it could eventually lead to a cultural suicide. Utoh - Ezeajugh aptly understood the inextricability of culture and theater in Africa when she avers that: 
African theater is a valid evidence of the people's culture and the totality of their ways of life over a given period. These include their socio-political and economic milieu, their philosophy and ethics as well as their historical development. [5]

It is on these bases that the study proposes an Annual/Contemporary Mmanwu festival for Anambra State Ministry of Information and Culture in the spirit of restoring meaning to things that are fast becoming meaningless, as Simeon Njom suggests; let us navigate the contradictions of this new century[6].

\subsection{Statement of the Problem}

African Cultures and Cultural practices came under the corrosive influences of modernization during the colonial period and the subsequent postcolonial era. This situation has made a lot of scholars to assume that there is an absence of any thread of continuity between works (both performing and visual arts) created during the pre-colonial era and those produced by the present generation of African Artists.

Contrary to their misleading speculation masquerade performances /festivals still exist in Africa and could be revitalized by reinventing them as modern festivals. This could in no little measure enhance tourism and economic gains of the people. Tradition Masquer festivals could be expanded to accommodate man's pre-occupation such as, national politics, western religion, technological innovations and their antecedents. The study therefore advances the idea that outside influences do not constitute danger to a virile tradition like masquerade festival rather it will help to sustain it.

\subsection{Purpose of the Study}

This study is set to prove that although Igbo masquerade festivals consist of mainly traditional performances, one can still observe the presence of all the necessary ingredients of modern theatre. These attributes qualify it as contemporary popular performance in its own right. Another objective of this study is to look at Igbo masquerade festival as a product for tourism and economic gains.

\subsection{Scope of the Study}

The study looks at the configuration of Igbo masquerade festival in Anambra State and the various dramatic and economic elements which it contains. In delineating these issues efforts were also made at interrogating traditional festival culture/tradition in other parts of Nigeria.

\subsection{Limitations of the Study}

The major problem that militated against this study is the noticed dearth of research materials in African traditional festivals in South East Nigeria, occupied by mostly people of
Igbo extraction. This meant that certain trends noticed during field work could not find ready opinions in written literature, especially on viewing traditional festivals as modern performances. The adverse economic condition in Nigeria equally militate against the research. This was felt most when my numerous respondents demanded for money before they could be interviewed or allow the researcher to take photographs of certain spectacles.

\subsection{Significance of the Study}

This study is significant in many ways. First, African masquerade festivals are rooted in the people's folklore and legend/myths, which is not only relevant but necessary if, folklore culture must assume its rightful place in the ranging debate on national development. The study also projects the idea that most scientific and technological invention have their bases on folklore. Some of the folk knowledge displayed during masquerade festivals in Africa are capable of forming a pedestal for modern technological inventions.

Secondly, this study projects a resilience of Igbo culture and tradition in the midst of eroding Western influences. It was equally observable that some performances and innovations witnessed during Igbo masquerade festival holds up a lot of promise for tourism, economic gain, social commentary through satire and the eccentricities of public lives.

\subsection{Methodology}

This work deals with the gathering, documentation and evaluation of performances idiom in Igbo traditional masquerade festivals. The study employed a survey research which according to Emeka Nwabueze "is very valuable in obtaining data on a non-observable phenomenon in order to learn the status of something" [7]. This involves field workcollection of data through interviews which was carried out among the local people and people working in tourism industry. Observations, practical demonstrations of traditional masquerade performers were also document. The study also used qualitative interpretative method. The equipment used in data collection include: tape recorder, photograph and computers. All these were helpful in scholarly recording and transcription of performance texts. The data for this work was basically gathered from both primary and secondary sources. The primary sources are mainly oral interviews, observations and participation both in the field and homes of key participants. The secondary sources are textbooks, thesis, magazines, bulletins, Newspapers, articles, seminar papers and journals in the area of traditional performance and traditional African art. Some of these were sourced through library research while some others were downloaded from the internet. In places where there is conflict of information between the primary and secondary sources, the primary source supersedes because there are expressed by first hand witnesses and insiders while books report information gathered from first hand witnesses 
might loose some facts in the process of translation and transcription.

\subsection{Area of the Study}

The study was carried out in Anambra State of Nigeria. Anambra State is one of the thirty-six states in Nigeria. It is located in the South Eastern part of the six geo-political zones in the country. The State is bounded in the East by Enugu State, in the West by Delta State, in the North by Kogi State and South by Abia and Imo States. The Capital City of Anambra is Awka, while the most commercial town is Onitsha.

The people in the area of study comprise, traders, farmers, artisans, civil and public servants. The major languages of the people are Igbo and English. In Anambra State, Tourism industry is not yet at its peak.

\subsection{Population of the Study}

The population of this study is 210 men from 21 local government areas of Anambra State. The choice of men for the study was predicated on the fact that masquerade performance is exclusively male prerogative in Igbo land. In addition about 30 persons who work in Anambra Ministry of Culture and Tourism and private Tourism Entrepreneurs were also selected for the study. They were interviewed using an interview guide and questionnaires were also administered to them.

\section{Igbo Masquerade Theatre as Drama}

In African Theater, three schools of thought exist and each differs in their view about African Theatre, such as the Mmanwu theatre under discussion. First is the Referentialists; who believe partly in the existence of African Drama. The protagonists of this theory include Ruth Fennigan, Kalu Uka among others. Kalu Uka, while writing on the Origin Africa Drama insists that;

African Drama is not yet Drama but contains Potentials which African drama can draw and draw with increasing returns. [8]

Another Referentialist theorist Echeruo, also declares that, "the so called Traditional African Drama is filed with ritual and until they are forced to yield their stories, that could not be considered as drama" [9]. Next are the Evolutionists who believe that drama evolved from rituals and festival. This school of thought separates drama from ritual, they see Africa traditional drama as rituals and insist that they don't contain enough theatrical elements to make one to consider them as drama.

The third is the Relativist school, spearheaded by Wole Soyinka and Ossie Enekwe. The relativist believe in Africa drama and insist that the drama of a people should be assessed based on the cultural ideology of that people [10]. Gowon Doki attributed the views of both referential list and the Evolutionist schools to the scholarly and intellectual phobia which characterized the continent at that time [11]. This view was upheld by Inih Ebong who summed up their views as an outcome of the curious pluralism of the confusing methodology and ambivalent standards in viewing drama only from Western viewpoints [12]. This study tows the line of the Relativist school and insists that the Igbo Mmanmu theater is complete drama just like any other Western drama.

\section{Igbo Mmanwu as a Tourist Event}

Mmanwu is a traditional masquerade of the Igbo people of Nigeria. The word Mmanwu literarily translates to the spirit of the dead". Masks are won to re-incarnate the spirits of the dead in a community. By wearing the mask, the masquerade or performer is believed to have spiritual powers that are conducted through the mask. Igbo masquerades perform both ritual and entertainment functions. Igbo masquerade tradition is patterned after the people's belief system and cosmology; masquerades also form a link between the living and the dead. Often times dead ancestors will visit their living relations in form of masquerades. These masquerades transform the spirit and make them visible to the living. Cole and Aniakor remark that, "masks are worn to give a real tangible form to the spirit world, here they could be beautiful or terrifying in outlook and worn with a variety of attachment". [13]

Mmanwu is a very fearful cult among the Igbo and their origin dates back to the ancient period. Membership of Mmanwu is male, although, one still finds out that the secrets of Mmanwu are not hidden from Nne Mmanwu (Menopausal women). Masquerades are communally owned by an age grade or entire community, however, in contemporary times, individuals can commission their own masquerades [Nwanna [14]. Masquerade performances could also be recorded in videos tapes and CD's for commercial purposes [Asigbo [15]

The identity of the masker is usually kept secret and he is referred to as the dead even when one known his identity. Prospective members of Mmanwu must be initiated into the society. Their identity is known only to other members. Masquerades act as the main sources of entertainment and agent for the enforcement of communal law and discipline. The Igbo Mmamwu theatre is a repository of Igbo creativity. The Mmanwu theatre is so enchanting that even the Local Audience still look at the scene in wonderment, as there is no real limit to the improvisations to which it lends to itself.

The Igbo have various types of masquerade that vary in form and size. Some are meant for the public (mostly entertainment masquerades). They also perform during festivals, while others are not meant to be viewed by the public, they are the Night Masquerades. These Night 
masquerades play the roles of securing the community and to punish or execute criminals. The most outstanding Igbo masquerade is the Ijele - a totemic characterization, majestic in stature and very colourful in design. Ijele which is about the size of traditional Igbo hut remains the biggest masquerade in Igbo land.

\section{Contemporary/Social Reality Masquerades}

One of the remarkable developments in Igbo land today, is the emergence of masquerades seeking to capture the follies of contemporary Nigeria with the view to uncovering the many mysteries surrounding many Social Conducts. These include: Police Masquerades, Politicians, Notable animals and birds such as Elephant, Eagle and Cattle. The "Politician Masquerade" are satirical masquerades that recreate the burdens and problems of Nigerian leaders an example of this type of mask is the Senator Chris Ngige Mask, fashioned to resemble the present minister for labour and former Governor of Anambra State. (See plate 1)

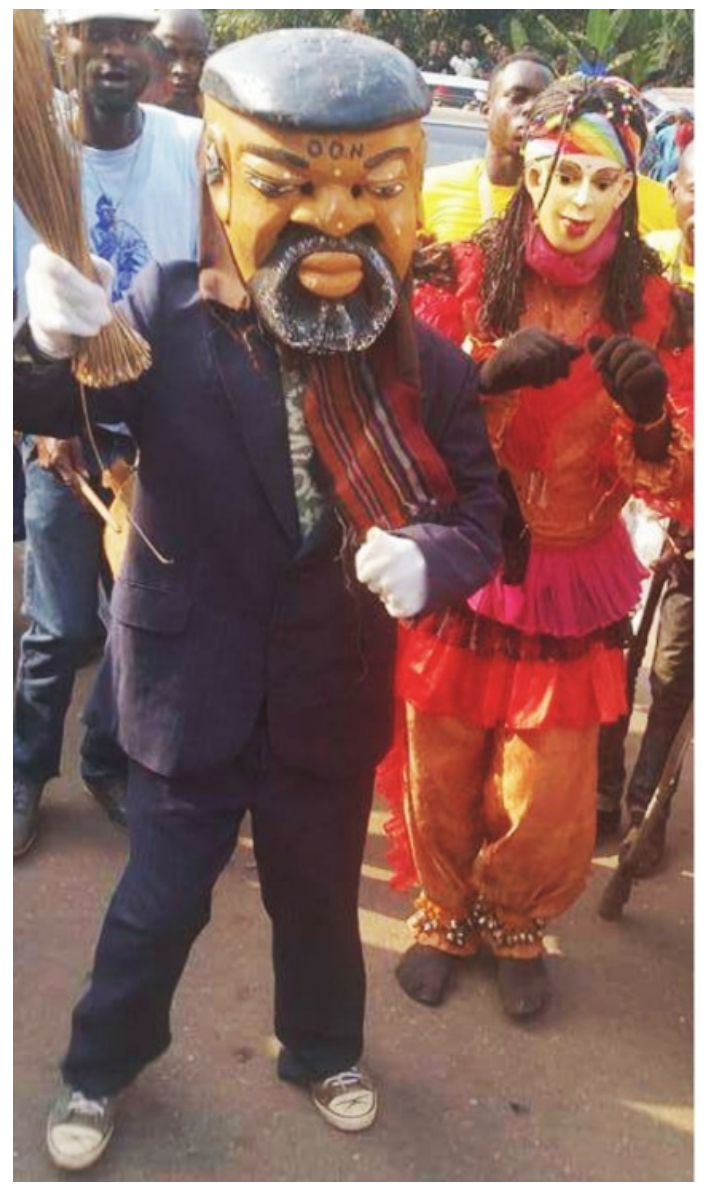

Plate 1. Chris NgigeMasquarde

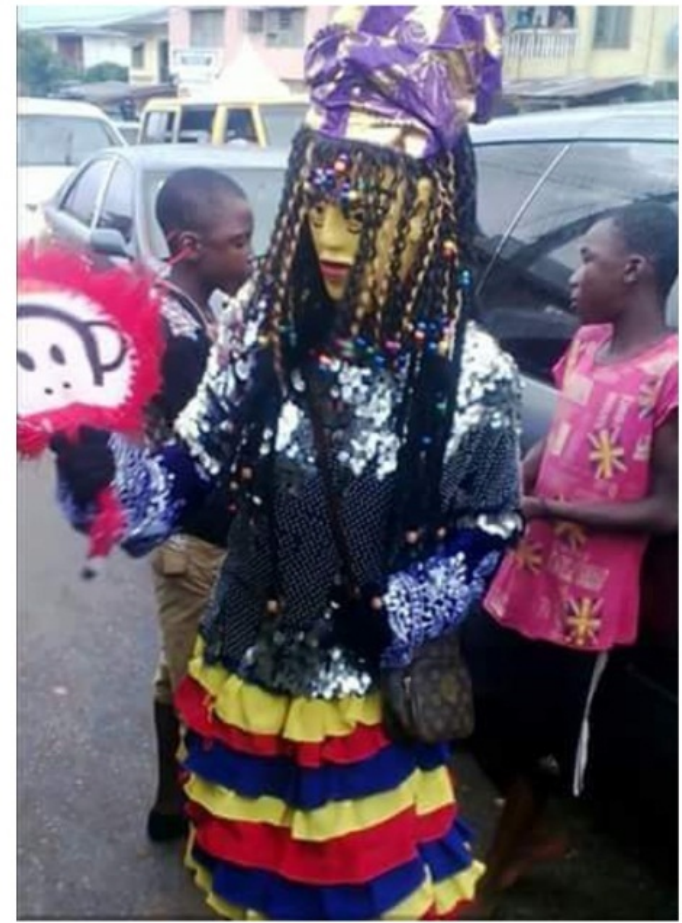

Plate 2. Adamma Masquarde

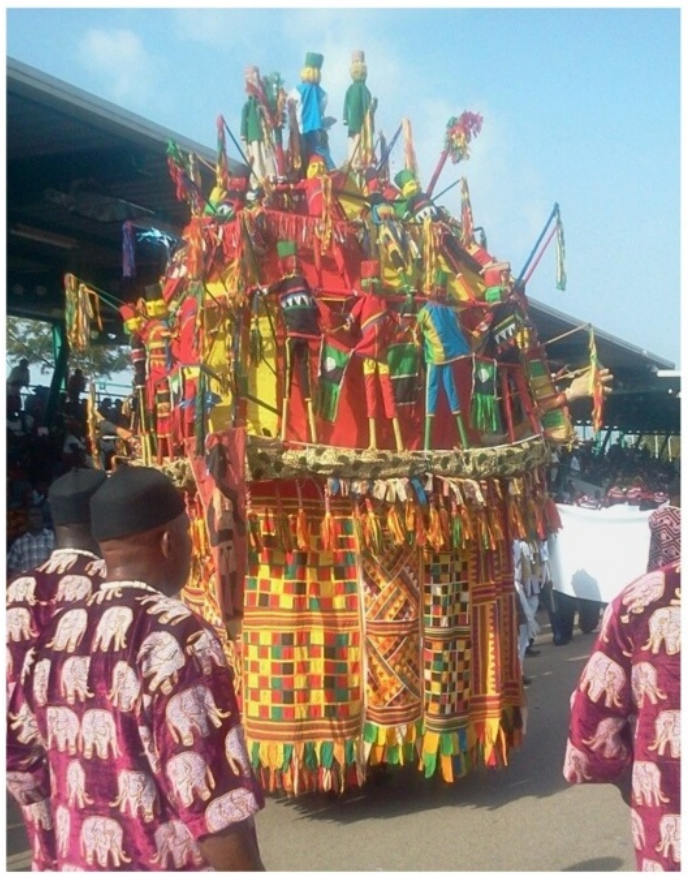

Plate 3. IjeleMasquarde

The concept of beauty and sexual perversity is given expression through the Adamma (Plate 2), Shaaba and Papa Loolo masquerades. The Adamma and Shaaba Masquerade are often constructed with well-endowed buttocks, coiled hair, protruding breasts and white teeth. These masquerades 
dance elegantly to the admiration of the audience. There are other contemporary masquerades such as Adamma masquerade and Ijele masquerade that teach morals to our computer age children. They are re-enacted to scare children from way-ward conducts.

\section{Organizing a Contemporary Masquerade Festival}

Organizing a contemporary masquerade festival starts with a conscious effort by the producer, appointing a technical crew. He should also consider the audience - what type of audience, age, sex and expected number. The area for the festival should be put into consideration, an open theatre is quite suitable for such festival spaces such as city stadium and large town or city square.

The next stage is to call for entries from all the interested Mmanwu groups in Anambra State. The groups that turned up shall be invited for rehearsal. Series of rehearsal shall be held but the final one shall be the dress and technical rehearsals. During this final rehearsal the performer shall put on their actual costumes and props as if it were the actual production. This will enable the producer to confirm that all is set for the D-day. While this rehearsal is going on, other members of technical crew will also be busy doing their work. The main work of the theater manager is to co-ordinate the workers. For example, the technical director will look at the venue and come up with a draft and blue print which he shows to the theater manager/producer. If the producer approves it than he will go on to produce the actual design. For a Mmanwu festival, an open theater can do, but the sitting arrangement of the audience and the room for the performance must be put into consideration. The technical manager will equally ensure that all the equipment, tools and material required for the construction are available. The appropriate scenery and properties should also be provided.

The time of the performance must also be considered. If the performance will extend into the night then lighting must be provided, sound and special effect should also be given top priority. Microphones, amplifiers and loudspeakers will be required to communicate with the audience along with special effect, when necessary.

\section{Aspects of Merchandise}

There must be arrangement for realizing money from the production while ensuring a full house. The first step is by establishing Box office which will be managed by box office manager. The box office manager will handle the sales of ticket to the audience and admitting them into the show. Some stadia and auditorium also have built in Box Office.

There should also be a recording of the performance of these masquerades in VCD's and DVD's; this can be sold to the members of the public later to realize money. Corporate groups should also be approached for part sponsorship of the show and in return they would have their product advertised during the show.

\section{Publicity}

When all is set the producer should write a preview of the upcoming performance and also press release in new paper and magazine. This will help to create awareness about the programme. Awareness could also be created through Jungle Publicity; where some of the performer will wear their costume and perform casually in town to advertise the upcoming shows; posters advertising the programme and flyers will be produced and pasted at different places. Jingles can be composed and played on radio as means of publicizing the show. When all is set, the show will be declared open with enough security personal to ensure order.

After a successful outing, the producer will then write a review of the production which will be published and marketed to make money. Businessmen could be encouraged to pay some money to the organizers and in turn produce memorabilia based on the festival which they can sell to the public.

Entertainment marketers could also obtain licenses and copyrights for fixed sum of money to enable them market the, CD's and other documented products from the festival. In all, the producer and the theatre manager with aim at ensuring a full house and a maximum profit.

\section{Summary of Findings}

Majority of the men (traditionalist) are aware of culture change in various aspects of Igbo Culture and anticipate more changes in future. Furthermore from the study, there is a significant awareness by Tourism entrepreneurs about carnivals and contemporary cultural festivals in other parts of the world. Since majority of the respondents have affirm that there is need to modify masquerade festivals in Anambra State one now see the need to organize such programmes like, orientation exercises, seminars and workshops that will be packaged in a way that it will include information on the danger or leaving our traditional masquerade festivals in a stagnant stage which many ultimately lead to an extinction of such cultural activity. Such orientation exercises should also emphasize the need for modernization of our traditional institutions with a view maintaining healthy relationship among the people and across the genders

\section{Conclusions}

Tourism industry in Nigeria has not been fully developed. This is regrettable especially when one reflects on the fact that the country with its over 200 ethnic groups holds a rich cultural heritage, amidst unique wildlife, and favourable climate. Nigeria did not establish an official tourist board 
until 1976. Although, efforts have presently sprang up in developing some sections of tourism in Nigeria, the masquerade festivals still remains an unfulfilled potential.

Masquerade festivals if properly harnessed and sustained could popularize the country globally and generate substantial income for her. It will also afford dance researchers and theater managers an opportunity and assistance to attempt at analyzing and recording, by films, sketches and dance notations the multiplicity of movements of our traditional carnival in order to preserve them for posterity.

The study presents a novel way of looking at African festival; as new vista for economic gain and not mere ritualistic festivals. The research also contained a lot of information which can encourage other researchers to work on African masquerade festivals and other similar subjects on African and other non-western cultures in line with the suggestion by Eric Bookhardt that "critics and art historians must necessarily try to tidy up the messy cultural shifts and convolutions that define certain times and places and their orderly taxonomies typically reflect some artists efforts more faithfully than other" [14]

\section{REFERENCES}

[1] World Tourism Organization (2013) Yearbook of Tourism statistics: compendium of Tourism statistics and data files, unwtorglen(retrieved $8^{\text {th }}$ July, 2015).

[2] Culture and Tourism in Anambra state, Anambra state blog spot.com, assessed on 18 April, 2017.

[3] Nigeria Tourism, www.abujafacts.ng. Assessed on 18 April, 2017

[4] Vansina, J. Art History in Africa, London: Longman Pub. 1993.
[5] Utoh - Ezeajugh, T. Dramatising a people's History as a parable for a nation in search of Peace: Alex Asigbo's Doxology as a paradigm, Awka: Theatre Experiences. Department of Theatre Arts, Nnamdi Azikiwe University 2014.

[6] Njami, S, The seeing power, Reenchantments: The city in the Blue Daylight, Dakar: DAK'ART, 2016

[7] Nwabueze, E. Research Methods: An integrated Approach ( $2^{\text {nd }}$ edition) Enugu: ABIC Books \& Equip Ltd, 2013.

[8] Uka, K New Direction in Theatrical Practice at Nsukka, an unpublished paper, 1975

[9] Ogunbiyi, Y. Nigeria Theatre and Drama: A Critical Profile, Drama and Theatre in Nigeria: A critical Source Book, A Nigeria Magazines Special Edition, Lagos: Department of Culture, Federal Ministry of Social Develop, Youth and Sports, 1981

[10] Enekwe, O. Myth, Ritual and Drama in Igboland, in Nigerian Theatre A Critical Source Book Nigeria magazine,(Yemi Ogunbiyi ed) Lagos: Federal ministry of Social Development, Youth and Sports, 1981

[11] Doki, G. Traditional Theatre in Perspective: Signs and Signification in Igbe, Girinya and Kwagh-hir, Abuja: Aboki Publishers, 2006.

[12] Ebong, I. Drama and Theatre among the Ibibio of South Eastern Nigeria: A case study of Utuekpe or Ekom Drama, $\mathrm{PhD}$ thesis, University of Birmingham, England 1990.

[13] Cole, H and Aniakor, C. Igbo Arts Community and Cosmos, Los Angeles: UCLA Press.

[14] Nwanna, C.E. Interrogating the Roots and Crossover: Egwu Imoka Festival in Awka, Awka: Nka na Uzu Magazine, 2014.

[15] Asigbo, A.C. From Ritual to Merchantile Arts: Ikeji Masquerade Festival of Aro Ndizuogu as Paradigm 2010, Awka: An, unpublished proposal.

[16] Bookhardt, Lynda Benglis: Ichoose my dreams, Hamilton: Sculpture Magazine 2017 